\title{
Students' epistemological beliefs, expectations, and learning physics: An international comparison
}

\author{
Sapna Sharma, ${ }^{1}$ P. K. Ahluwalia, ${ }^{2}$ and S. K. Sharma ${ }^{3}$ \\ ${ }^{1}$ Department of Physics, St. Bede's College, Shimla 171 002, India \\ ${ }^{2}$ Department of Physics, Himachal Pradesh University, Shimla 171 005, India \\ ${ }^{3}$ Department of Statistics, Panjab University, Chandigarh 160014, India
}

(Received 18 April 2012; published 30 April 2013)

\begin{abstract}
It has been established by physics education researchers that there is a correlation between the learner's behavior, their epistemological beliefs with which they come to the classrooms, and their success in a course. This study of Indian students and teachers explores expectations and beliefs in learning physics at the secondary and tertiary levels by making use of the Maryland Physics Expectation (MPEX) survey, which has been tested for both its validity and its reliability. The MPEX was administered to a sample of 265 Indian students at three different levels of study: (i) XII standard (high school), (ii) undergraduate (Bachelor of Science), and (iii) master's degree (Master of Science in Physics, MS). In India, a pre-post instruction difference between the attitudes of class XII, undergraduate, and master's students is observed with favorable improvement in master's students as compared to deterioration in both class XII and undergraduate students. A comparison of these results with those reported in similar studies conducted in four other countries (U.S., Turkey, Philippines, and Thailand) indicates that there is a difference between the U.S. students and those of the other three countries and also between U.S. experts and Indian teachers. In all countries (U.S., India, Turkey, Thailand, and Philippines) the basic trend of expectation from pre to post test remained the same-there was a deterioration observed in all levels of students. Indian MS students were an exception. A significant difference was observed in the expectations of U.S. experts and Indian teachers. The score of favorable views of Indian class XII and undergraduate students was observed to be less than U.S. students in many clusters. No significant difference was found between Indian male and female students' expectations at any level of study. This study shows that most Indian students have nowhere near an expert's expectations even after instruction, which might affect their motivation and success in physics courses and may have long-term implications on the quality of physics education in schools, colleges. and universities and the scientific research aspirations of the country.
\end{abstract}

DOI: 10.1103/PhysRevSTPER.9.010117

PACS numbers: 01.40.- d

\section{INTRODUCTION}

Epistemology is a branch of philosophy which deals with the study of knowledge and beliefs. In the context of science, epistemology deals with the nature of science and scientific knowledge by raising questions such as (i) how we know what we know, (ii) how to create new knowledge, (iii) how one draws inferences, and (iv) how one makes sense. Students' epistemological beliefs and attitudes have great impact on their approaches of learning and time spent on organizing their knowledge structure. Educational researchers characterize epistemological beliefs in different ways. Schommer characterized epistemological beliefs as a system made of almost independent dimensions about knowledge and knowing [1]. Research has shown that students' expectations in physics, which emanate from attitudes, beliefs, and assumptions about

Published by the American Physical Society under the terms of the Creative Commons Attribution 3.0 License. Further distribution of this work must maintain attribution to the author(s) and the published article's title, journal citation, and DOI. physics, decide their future course of learning and hence play a very important role in the conceptual understanding of physics [2,3]. Expectations incorporate learners' ideas of what comprises physics learning, as well as their thoughts about their own role in the learning process, i.e., what is expected from them? Sherin defines knowledge that is gained prior to formal instructions as perceptive beliefs or common-sense knowledge because it is based on prior beliefs [4]. Sometimes these prior beliefs can lead to different understandings of the same situations by different learners. According to Redish each student brings a set of attitudes, beliefs, and assumptions about what sorts of things he or she will learn, what skills will be required, and what he or she will be expected to do in the physics class [5]. It has indeed been established that students' responses actually depend upon their expectations, and consequently their expectations affect their understanding of the subject [6-10]. Physics education researchers have focused a lot of attention on understanding and evaluating various dimensions of epistemological beliefs and attitudes held by experts and novices $[11,12]$. They have also investigated the possible relation between the learning behavior of 
students and epistemological beliefs $[13,14]$ with which they come to the classroom and which strongly influences their transition from a novice to an expert. Thus, the awareness of preknowledge or learner's perception plays a very important role for the instructor to plan his or her teaching activities to make students link new material to what they already know. Relying on this fact, researchers have also developed curricula to improve student's attitudes [15-17].

There are number of surveys that have been developed, mainly by physics education researchers, to measure the influence of epistemological beliefs and expectations on physics learning. They are the Maryland Physics Expectation (MPEX) survey developed by Redish et al. [5], View About Science Survey (VASS) developed by Halloun and Hestenes [18], Epistemological Beliefs Assessment for Physics Science Survey (EBAPS) by Elby et al. [19], and Colorado Learning Attitudes about Science Survey (CLASS) by Adams et al. [20]. These surveys, known as attitude surveys or affective surveys, probe learner's thinking about the process and the character of learning physics. They provide useful information on students' perception of their classroom experience to measure the perceptions systematically and quantitatively. They are different from the so-called content surveys, which aim to identify learning gaps or misconceptions in the subject and bring out learners' perceptions on the content of a course, the effects of course innovations, etc. The attitude surveys focus on students' needs in taking a course, how well those needs are being met, their interest in or appreciation for the subject matter or field, students' confidence in their ability to perform in a course, and their beliefs about the nature of the discipline itself (e.g., chemistry, physics, mathematics, and engineering). The advantage of these survey instruments is that they can be administered on a large group of students in a very short period and the responses can be analyzed on a computer. A number of studies have been carried out using these instruments in the same form or suitably adapted to new science domains (biology, physics, chemistry, etc.) but having similar focus on epistemology and expectations [21,22].

In the present study, we have made use of the MPEX survey to probe and understand the influence of epistemological beliefs on Indian students' journey from a novice to an expert. The MPEX survey has been developed by Redish and is designed to elucidate students' attitudes along six specific dimensions to probe various aspects of student expectations [5]. In addition, the MPEX survey is well tested for both reliability and validity. It was validated by studying the results of chosen groups after more than 120 hours of student interviews conducted by the Maryland Physics Education Research group. Cronbach's alpha coefficient for the survey is 0.81 , which means the survey is quite reliable. The survey consists of 34 items divided into different clusters that probe students' attitudes and beliefs about physics and learning of physics. Students are asked to respond to the statements using a 5-point Likert scale.

The MPEX survey explores student's beliefs divided into six clusters: independence, coherence, concepts, reality link, math link, and effort link. The independence cluster questions probe whether the students are taking the knowledge being received from an authority or are

TABLE I. Cognitive structure of student expectations on learning physics [22].

\begin{tabular}{|c|c|c|c|c|}
\hline Clusters & $\begin{array}{l}\text { Dimension using } \\
\text { Bloom taxonomy: } \\
\text { physics learning }\end{array}$ & Favorable (expert view) & Unfavorable (novice view) & MPEX items \\
\hline Independence & By rote & $\begin{array}{l}\text { To take responsibility for } \\
\text { constructing own } \\
\text { understanding }\end{array}$ & $\begin{array}{l}\text { To take what is given by } \\
\text { authorities (teacher, text) } \\
\text { without evaluation }\end{array}$ & $1,8,13,14,17,27$ \\
\hline Coherence & By relation & $\begin{array}{l}\text { To believe physics needs to be } \\
\text { considered as a connected } \\
\text { consistent framework }\end{array}$ & $\begin{array}{l}\text { To believe physics can be } \\
\text { related as unrelated } \\
\text { facts or pieces }\end{array}$ & $12,15,16,21,29$ \\
\hline Concept & By comprehension & $\begin{array}{l}\text { To stress understanding of the } \\
\text { underlying ideas and concepts }\end{array}$ & $\begin{array}{l}\text { To focus on memorizing and } \\
\text { using formulas }\end{array}$ & $4,14,19,23,26,27$ \\
\hline Reality link & $\begin{array}{l}\text { Through formula } \\
\text { derivation }\end{array}$ & $\begin{array}{l}\text { To believe ideas learned in physics } \\
\text { are relevant and useful in wide } \\
\text { variety of real contexts }\end{array}$ & $\begin{array}{l}\text { To believe ideas learned in } \\
\text { physics has little relation } \\
\text { to experience outside } \\
\text { the classroom }\end{array}$ & $10,18,22,25$ \\
\hline Math link & Through effort & $\begin{array}{l}\text { To consider mathematics as a } \\
\text { convenient way of representing } \\
\text { physical phenomena }\end{array}$ & $\begin{array}{l}\text { To view physics and math as } \\
\text { independent entities with } \\
\text { little relationship } \\
\text { between them }\end{array}$ & $2,6,8,16,20$ \\
\hline Effort link & Through practice & $\begin{array}{l}\text { To make the effort to use } \\
\text { information available and } \\
\text { tried to make sense of it }\end{array}$ & $\begin{array}{l}\text { To not attempt to use } \\
\text { available information } \\
\text { effectively }\end{array}$ & $3,6,7,24,31$ \\
\hline
\end{tabular}


acquiring the knowledge through personal understanding, application, and modification. The coherence questions probe students' views of physics either as a collection of unrelated facts or as a single coherent system for describing the physical world. The concepts questions probe whether the student believes physics is just a collection of facts, formulas, and procedures or considers it as a body of concepts providing a foundation to their representation in terms of formulas and equations so that one gains the ability to explain the terms clearly in a qualitative way.

The reality link questions probe whether the student understands the relevance and use of physics in a real context. The math link tries to probe whether students are able to consider mathematics as a convenient tool to represent physics or if they consider mathematics and physics as two independent entities having no link with each other.

The responses to the statements are further categorized, as presented in Table I, as favorable, if they agree with the expert (experienced physics instructors view), and unfavorable (novice view), if they do not. Table I also identifies to which dimension of Bloom's taxonomy each element of identified cognitive structure belongs.

This paper is organized as follows. Section II explains the purpose of the present study in the Indian context. Section III briefly highlights the research questions. Section IV gives the details of methodology employed, the mode adopted in administering the survey, and the sample taken. Section V gives a detailed statistical and graphical analysis of the results obtained followed by a discussion in light of the research questions posed for the study undertaken in this work. Section VI summarizes the results and discusses implications.

\section{CONTEXT AND PURPOSE OF STUDY}

The purpose of this study is to discuss such an instrument with the teachers so as to sensitize them to the issues about expectations and beliefs, which they seldom care about, and help them go beyond a routine, definitions and derivations-based, teaching learning syndrome. This effort can facilitate open doors for the students to become creative and better critical learners.

In India, it is being increasingly observed that there is declining interest among students to opt for basic sciences. It may be because of fundamental conceptual difficulties involved in learning of basic sciences as many students think these subjects are too demanding, with very few lucrative professional choices available for future as compared to other subject domains. Also the relevance of the subject to everyday life and practical applications may not be very clear to the students, which naturally gets translated into a lack of interest and effort required to learn the subject. It is generally felt that there is a need to motivate students' towards science in general and physics, in particular, and this requires creativity and innovations on the part of instructors. Currently, there is a lot of public effort in the country to retain good students in basic sciences. The government of India has initiated a very innovative countrywide program called "Innovation in Scientific Pursuit for Inspired Research" (INSPIRE) to attract talented students to study science. In this program students currently studying in the class $10+1$ (XI) and $10+2$ (XII) stages, with scores above $80 \%$, are selected on the basis of their performance at the high school level. The students are brought together in a group to a week-long camp to motivate them to study science by listening to lectures of working scientists and experts and through participation in various activities designed to encourage them towards basic sciences. This kind of an exercise no doubt inspires students over a short period, but likely does not help in converting their belief structure into an expert's belief structure, because of weak follow-up action. Additionally, no systematic study has been made in this direction to map the differences at local and national levels.

We had detailed discussions with peer groups working in apex national agencies of the country (India), like the National Council for Educational Research and Training (NCERT), New Delhi, and Homi Bhabha Centre for Science Education (HBSCE), Mumbai. Both of these institutions are involved in paving the way for quality science education in India through development of textbooks, resource material for classrooms, and by introduction of various innovative programs for students and teachers at school and undergraduate level. NCERT has regional colleges in various states of the country specifically targeted to teacher training for school education. HBCSE works with a goal to promote excellence in science education from primary school to undergraduate college level, and encourages the dissemination of scientific literacy in the country.

Also, the recent report of Programme for International Student Assessment (PISA) for 15-year olds in reading, mathematics, and science caught our attention. The report revealed that students in India fared below the overall international average. The survey included two states of India, namely, Himachal Pradesh and Kerala, one of which (Himachal Pradesh) is the context for the present study, and are the top two states of the country with highest literacy. These two states ended near the bottom of the participant countries with mean scores of 337 and 325, respectively, providing a wake-up call for India's education system [23]. The report also recommends that policy makers should take research-based findings into account when considering reforms of skill development, learning, and testing practices and consider approaches to education to address the individual differences of students' motivation and attitudes.

Thus, knowledge of the attitudes of students in the classroom regarding a particular subject he or she is learning has become the need of the hour. Current indicators very strongly suggest that there is a need for research on epistemology, which should help in improving the learning of physics as a subject by the learners. 


\section{RESEARCH QUESTIONS}

This study seeks to support national efforts of educational improvement in India by providing information about student epistemology at different levels of the educational system. The results of such a study are also interesting from the perspective of international comparisons. This research extends the available information about student expectations in physics beyond those cultural backgrounds in which the MPEX was designed and previously applied $[16,24,25]$.

This type of study can help to address broader questions related to the effect of different cultural settings on student expectations. Furthermore, there have been relatively few prior studies investigating changes in student epistemology after instruction [26-29]. But the present study highlights the change in epistemology of students as they progress from school to undergraduate physics degree study to master's degree study. This type of research may help to provide the physics education research (PER) community with fresh insights towards new ways and means to use epistemic resources and epistemic frames to take the learner towards an expert view.

This study addresses the following research questions.

(i) How do the attitudes and expectations of Indian physics students compare between class XII (high school), undergraduate (UG), and master's degree (MS) levels of study?

(ii) How do these expectations shift during before (pre) and after (post) instruction at each level?

(iii) Is there a difference in attitudes expectation between male and female students?

(iv) How do the attitudes and expectations of Indian students compare to those of other countries for which comparison data is available?

\section{METHODOLOGY}

To conduct the study, the items of MPEX survey were translated into Hindi, the national language of India, and administered in a bilingual format to facilitate easy comprehension and neutralize linguistic differences which may crop up, since English is not their native language. The translated portion was vetted by five teachers teaching physics at the undergraduate level to ensure that the meaning of the translated items did not get altered. The structure of the survey was kept the same.

The survey was administered to 228 students (XII and undergraduate) studying in Shimla and Mandi districts of Himachal Pradesh state and to 37 students (MS) studying for their master's degree in Kurukshetra University (KU) in the Kurukshetra district of neighboring Haryana state of India, at the beginning and at the end of instruction for the year (2010-2011). In total there were 265 (155 female and 110 male) students. At class XII level, students study an introductory course of physics. At the undergraduate level,
Bachelor of Science (B.Sc.) students study nine special basic courses of physics over a duration of three years. At the master's degree level, students study advanced courses of physics over a duration of four semesters. All the surveyed students received instruction through traditional lecture method alone.

In addition, the survey was also administered, only once, to a group of 40 school, college, and university teachers from across the country teaching physics. College and university teachers took the survey during a refresher course in physics at Academic Staff College, Himachal Pradesh University Shimla. As regards academic preparation of teachers, in India the teachers teaching physics in schools to class XII students are MS in physics with a Bachelor of Education (B.Ed.) teacher training degree. The B.Ed. degree is mandatory for teaching in schools. The teachers teaching in undergraduate colleges need to have a M.Sc. as well as a Master of Philosophy (M.Phil.) degree in the concerned subject. Additionally, they also have to qualify on a national level eligibility test (NET) in their subject to be eligible for teaching in the colleges or universities of the country. This test is composed of two parts. The first part is on general aptitude and the second is on scholastic aptitude of the concerned subject (physics). This test does not assess their teaching abilities or preparation for teaching. All the teacher participants as well as surveyed students took about half an hour to complete this survey. The breakdown of the sample is given in Table II. Further, the institutional affiliation of the surveyed students in this study is as given below.

- Class XII students were from five different schools of the state of Himachal Pradesh, India. Four of these schools were private (also known as public schools in India) and one was a reputed government school. These students fall in the age group of 17-18 years, as that of the students studying in the high school in the U.S., undergoing algebra-based physics curriculum.

- Undergraduate (B.Sc.) students were from a local women's college, affiliated with Himachal Pradesh University, Shimla, India, where Sapna Sharma is an associate professor. These students were in the final year of their three year B.Sc. degree program.

- Master's degree (M.Sc. physics) students were from the Department of Physics, Kurukshetra University, Kurukshetra, India. These students were studying in their second semester of four semesters, spread over two years, M.Sc. (physics) degree program.

TABLE II. Sample of students (India).

\begin{tabular}{lccc}
\hline \hline Class & Total & Male & Female \\
\hline XII (high school) & 200 & 104 & 96 \\
UG (undergraduate) & 28 & Nil & 28 \\
$\begin{array}{l}\text { MS (Master of Science) } \\
\text { physics students }\end{array}$ & 37 & 6 & 31 \\
\begin{tabular}{l} 
Teachers \\
\hline \hline
\end{tabular} & 40 & 33 & 7 \\
\hline
\end{tabular}




\section{RESULTS, STATISTICAL ANALYSIS, AND DISCUSSION}

In this section, we discuss the results obtained and inferences drawn from administering the MPEX survey to students at the beginning and the end of the instruction of courses of physics and to teachers attending the refresher course once during the course. The analysis is presented in four parts. In Sec. VA we describe the methodology adopted for analyzing clusterwise responses. In Sec. VB genderwise analysis is done, in Sec. VC the overall scenario is presented, and in Sec. VD a countrywise comparison is made.

\section{A. Clusterwise analysis and inferences}

As stated earlier, the responses that were chosen by the experts and which were most commonly found in the enthusiastic, self-motivated learners were called favorable. The responses that disagree with experts and were often chosen by students who were more concerned with grades than with learning were called unfavorable. A choice of numbers 4 or 5 was taken as response "A," which included either of the two options agree or strongly agree. Whereas a choice of numbers 1 or 2 was taken as response "D," which again included either of the two options disagree or strongly disagree. The choice of Likert number 3 was taken as neutral [5].

To visualize the results in a concise and easily interpretable manner, agree-disagree (A-D) graphs have been plotted. Such clusterwise graphs show the relationship between the percentage of candidates answering favorably to the percentage of candidates answering unfavorably for each group. Since the sum of the fraction of students agreeing and disagreeing must be less than or equal to $100 \%$, all points must lie in the lower triangle bounded by the corner coordinates $(0,0),(0,100),(100,0)$. The distance of a data point from the diagonal line is a measure of the number of candidates who either answered with the neutral choice or did not answer at all. The closer a point is to the upper left corner of the allowed region, i.e., $(0,100)$, the better the group's agreement with the expert response in a particular cluster.

The survey data were further analyzed by determining the ratio of favorable to unfavorable responses for each of these categories. Table III gives the percentage of favorable to unfavorable responses given by university students, college students, and school students, respectively, on overall MPEX survey and clusters of the MPEX survey for pre and post tests in India and other countries. The data for the U.S. were taken from the Redish et al. study [5], for Thailand from the Chanprasert study [30], for Turkey from the Mehmet study [31], and for Philippines from the Dalagan study [32] respectively. The table shows that students from the U.S. were having more expertlike views than students from India, Turkey, Thailand, and Philippines.
To statistically analyze the data and to see the correlation within the groups and across the groups for our sample of Indian students and teachers, we plotted normal quantile ( $Q-Q$ plots, not shown here) using sPSs for all the six clusters and observed that the "independence" and "math link" clusters had normal distribution whereas the "coherence," "concept," "reality link," and "effort link" clusters had nonnormal distributions. Therefore, on normally distributed clusters parametric tests were applied and on non-normally distributed clusters nonparametric tests were applied.

(i) Parametric tests. As mentioned above, since the independence and math link clusters had normal distribution, we applied a parametric test on them. In order to see the significant difference between all four categories (XII, UG, MS, and teachers) in these clusters, we applied one-way analysis of variance (ANOVA) and found that in both the clusters there was a significant difference between all the four categories $(p<0.05)$. The ANOVA results are presented in Table IV.

Further, for comparison and to find which pairs differ significantly, we applied the post hoc Scheffe test. Significant differences were observed in all of the pairs in the independence cluster $(p<0.05)$ except in the pairs of UG students and teachers $(p=0.39)$ and XII students and teachers $(p=0.84)$. A similar comparison made for the math link cluster showed that all pairs differ significantly $(p<0.05)$, except UG and XII students ( $p=0.13)$, UG students and teachers $(p=0.28)$, and XII students and teachers $(p=1.0)$. Scheffe homogeneous subset selection results showed that the MS students category belongs to the first subset while all other categories (teachers, XII, and UG students) belong to the second subset for both the independence and math link clusters.

(ii) Nonparametric test. Similarly, we applied the Kruskal-Wallis nonparametric test to the concept, coherence, reality link, and effort link clusters because the data were not normally distributed for these clusters. The Kruskal-Wallis nonparametric test was applied for comparison among more than two groups and the Mann-Whitney test for comparison between two groups only. The Kruskal-Wallis test, Table V, showed that the three clusters Coherence, Concepts, and Effort link differ significantly with respect to all the four categories [teachers, MS, UG, and XII students $(p<0.05)$ ]. However, for the reality link cluster there was no significant difference in these categories $(p=0.20)$. The Mann-Whitney test, Table VI, showed significant differences across different categories. A negative $Z$ score indicates that the original score is below the median and a positive $Z$ score indicates that the original score is above the median. All negative $Z$ 
TABLE III. Percentage response ratio (favorable to unfavorable) of students, overall and clusterwise, for pre and post test in U.S., India Turkey, Thailand, and Philippines. First data row refers to experts (U.S.) view. Second data row refers to teachers (India) view

\begin{tabular}{|c|c|c|c|c|c|c|c|c|}
\hline Groups & Overall & Independence & Coherence & Concept & Reality link & Math link & Effort link & $N$ \\
\hline \multicolumn{9}{|c|}{ Experts (U.S.) [5] } \\
\hline & $87 / 6$ & $93 / 3$ & $85 / 12$ & $89 / 6$ & $93 / 3$ & $92 / 4$ & $85 / 4$ & $\cdots$ \\
\hline \multicolumn{9}{|c|}{ Teachers (India) } \\
\hline & $66 / 31$ & $57 / 39$ & $54 / 44$ & $61 / 37$ & $76 / 21$ & $61 / 36$ & $81 / 19$ & 40 \\
\hline \multicolumn{9}{|c|}{ University of Maryland College Park (UMCP) (U.S.) [5] (MS) } \\
\hline Pre & $54 / 23$ & $54 / 25$ & $53 / 24$ & $42 / 35$ & $61 / 14$ & $67 / 17$ & $67 / 13$ & 445 \\
\hline Post & $49 / 25$ & $48 / 27$ & $49 / 27$ & $44 / 32$ & $58 / 18$ & $59 / 20$ & $48 / 27$ & 445 \\
\hline \multicolumn{9}{|c|}{ University of Minnesota (UMN) (U.S.) [5] (MS) } \\
\hline Pre & $59 / 18$ & $59 / 19$ & $57 / 20$ & $45 / 27$ & $72 / 9$ & $72 / 11$ & $72 / 11$ & 467 \\
\hline Post & $57 / 20$ & $58 / 20$ & $61 / 17$ & $46 / 28$ & $69 / 10$ & $72 / 12$ & $63 / 16$ & 467 \\
\hline \multicolumn{9}{|c|}{ Ohio State University (OSU) (U.S.) [5] (MS) } \\
\hline Pre & $53 / 23$ & $51 / 24$ & $52 / 21$ & $37 / 36$ & $65 / 10$ & $65 / 13$ & $66 / 16$ & 445 \\
\hline Post & $45 / 28$ & $46 / 28$ & $46 / 26$ & $35 / 35$ & $54 / 17$ & $55 / 20$ & $44 / 30$ & 445 \\
\hline \multicolumn{9}{|c|}{ Dickinson College (DC) (U.S.) [5] (UG) } \\
\hline Pre & $61 / 15$ & $62 / 14$ & $58 / 17$ & $47 / 23$ & $76 / 4$ & $70 / 10$ & $75 / 7$ & 115 \\
\hline Post & $60 / 19$ & $67 / 14$ & $66 / 18$ & $58 / 23$ & $72 / 19$ & $71 / 12$ & $57 / 26$ & 115 \\
\hline \multicolumn{9}{|c|}{ Public Liberal Arts University (PLA) (U.S.) [5] (UG) } \\
\hline Pre & $57 / 23$ & $57 / 27$ & $57 / 26$ & $38 / 46$ & $71 / 13$ & $74 / 11$ & $72 / 8$ & 12 \\
\hline Post & $49 / 21$ & $52 / 22$ & $47 / 33$ & $45 / 34$ & $52 / 25$ & $54 / 19$ & $48 / 30$ & 12 \\
\hline \multicolumn{9}{|c|}{ TYC (U.S.) [5](high school) } \\
\hline Pre & $55 / 22$ & $41 / 29$ & $50 / 21$ & $30 / 42$ & $69 / 16$ & $58 / 17$ & $80 / 8$ & 44 \\
\hline Post & $49 / 26$ & $42 / 32$ & $48 / 29$ & $35 / 41$ & $58 / 17$ & $58 / 18$ & $65 / 21$ & 44 \\
\hline \multicolumn{9}{|c|}{ Master's of physics (MS) India } \\
\hline Pre & $60 / 33$ & $45 / 47$ & $39 / 50$ & $57 / 35$ & $80 / 13$ & $63 / 30$ & $73 / 23$ & 37 \\
\hline Post & $67 / 29$ & $64 / 31$ & $41 / 52$ & $59 / 36$ & $86 / 11$ & $66 / 27$ & $69 / 25$ & 37 \\
\hline \multicolumn{9}{|c|}{ Undergraduate (UG) India } \\
\hline Pre & $53 / 35$ & $29 / 61$ & $35 / 49$ & $43 / 42$ & $66 / 18$ & $56 / 34$ & $76 / 16$ & 28 \\
\hline Post & $40 / 40$ & $20 / 67$ & $23 / 48$ & $31 / 46$ & $52 / 25$ & $36 / 43$ & $64 / 22$ & 28 \\
\hline \multicolumn{9}{|c|}{ High school (XII) India } \\
\hline Pre & $55 / 35$ & $35 / 55$ & $34 / 53$ & $49 / 41$ & $67 / 23$ & $54 / 34$ & $70 / 22$ & 200 \\
\hline Post & $46 / 36$ & $33 / 50$ & $27 / 51$ & $46 / 36$ & $55 / 26$ & $48 / 34$ & $61 / 23$ & 200 \\
\hline \multicolumn{9}{|c|}{ DEU (Turkey) [31] } \\
\hline Pre & $44 / 32$ & $34 / 41$ & $38 / 37$ & $39 / 36$ & $53 / 21$ & $45 / 32$ & $51 / 26$ & 164 \\
\hline Post & $38 / 35$ & $31 / 41$ & $31 / 40$ & $38 / 36$ & $45 / 28$ & $38 / 32$ & $47 / 28$ & 164 \\
\hline \multicolumn{9}{|c|}{ UG (Thailand) [30] } \\
\hline Pre & $45 / 16$ & $48 / 14$ & $45 / 12$ & $49 / 11$ & $47 / 18$ & $41 / 17$ & $45 / 16$ & 100 \\
\hline \multicolumn{9}{|c|}{ UG (Philippines) [32] } \\
\hline Pre & $44 / 28$ & $38 / 31$ & $30 / 39$ & $27 / 47$ & $57 / 16$ & $44 / 26$ & $70 / 11$ & 92 \\
\hline Post & $47 / 30$ & $42 / 31$ & $32 / 41$ & $30 / 48$ & $59 / 19$ & $47 / 28$ & $72 / 11$ & 92 \\
\hline
\end{tabular}

TABLE IV. Analysis of variance for independence and math link.

\begin{tabular}{llcrrr}
\hline \hline Cluster & & Sum of squares & d.o.f. & Mean square & $F$ \\
\hline Independence & Between groups & 729.776 & 3 & 243.259 & 14.517 \\
& Within groups & 5043.876 & 301 & 16.757 & $0.001^{\mathrm{a}}$ \\
& Total & 5773.652 & 304 & & \\
Math & Between groups & 244.742 & 3 & 81.581 & 7.917 \\
& Within groups & 3101.697 & 301 & 10.305 & $0.001^{\mathrm{a}}$ \\
& Total & 3346.439 & 304 & & \\
\hline \hline
\end{tabular}

\footnotetext{
${ }^{\mathrm{a}}$ Highly significant.
} 
TABLE V. Kruskal-Wallis nonparametric test.

\begin{tabular}{llrccc}
\hline \hline Cluster & Group & $N$ & Mean rank & Chi-square & $p$ value \\
\hline Coherence & UG & 28 & 165.88 & 9.150 & 0.027 \\
& MS & 37 & 146.76 & & \\
& XII & 200 & 159.77 & & \\
& Teachers & 40 & 115.90 & & \\
& Total & 305 & & & \\
Concepts & UG & 28 & 169.43 & 15.874 & 0.001 \\
& MS & 37 & 145.28 & & \\
& XII & 200 & 161.94 & & \\
& Teachers & 40 & 103.92 & & \\
Efforts & Total & 305 & & & \\
& UG & 28 & 145.73 & 15.478 & 0.001 \\
& MS & 37 & 123.50 & & \\
& XII & 200 & 150.32 & & \\
& Teachers & 40 & 198.78 & & \\
& Total & 305 & & & \\
Reality & UG & 28 & 182.57 & 4.616 & 0.202 \\
& MS & 37 & 139.30 & & \\
& XII & 200 & 149.96 & & \\
& Teachers & 40 & 160.20 & & \\
& Total & 305 & & & \\
\hline \hline
\end{tabular}

values in Table VI reveal that for the studied sample the original score for all the clusters was below the median value.

(iii) Agree-disagree plots. Also to understand what is happening in different dimensions of student expectations in various groups, following Redish [5], we have drawn the clusterwise A-D plots for our sample of Indian students and teachers, where the level of expert views from the MPEX survey is also shown, to make a comparison with U.S. expert's beliefs and expectations for each cluster.

In the agree-disagree (A-D) plot, the percentage of students answering favorably versus the percentage of students answering unfavorably is plotted; see Figs. 1(a)-1(f), respectively, for the six studied clusters that have been drawn. A diagonal has

TABLE VI. Mann-Whitney test for comparison between categories.

\begin{tabular}{llll}
\hline \hline Cluster & Categories & $Z$ value & $p$ value \\
\hline Reality & UG versus MS & -2.184 & 0.029 \\
& students & & \\
Coherence & UG students & -2.536 & 0.011 \\
Concepts & versus teachers & -3.401 & 0.001 \\
Effort & & -2.607 & 0.009 \\
Concepts & MS students & -2.367 & 0.018 \\
Effort & versus teachers & -3.855 & 0.001 \\
Coherence & XII students & -2.784 & 0.005 \\
Concepts & versus teachers & -3.664 & 0.000 \\
Effort & & -3.134 & 0.002 \\
\hline \hline
\end{tabular}

been drawn as a guide to the eye to visualize how many respondents chose to remain neutral or opted not to respond. The closeness of a data point to the upper left corner $(0,100)$ means that there is good agreement between students' response and experts' response. The farther a point is from the diagonal, the more are the students who opted to remain neutral or decided not to respond.

Since standard errors are always useful to construct a confidence interval for the mean and also since most of the time statistical decisions are more appropriate based on confidence interval rather than based on a single value of the mean, the standard error bars in all the plots for favorable responses have been drawn. Error bars in the plots represent standard errors of individual variables plus standard error of the mean.

\section{Independence cluster}

There were six items in this cluster. According to the expert group the students should disagree with these items. Disagreeing with these items indicates that students were more dynamic and active learners. We found that initial favorable views in this dimension were in the range $29 \%$ (UG) to 45\% (MS) [Fig. 1(a)]. According to Redish [5] the shift of 5\% in student's response is significant. Thus, there was a significant increase in MS score (64\%) after instructions. Both UG and class XII students showed a decline in the score. Thus, MS students agree that learning physics means constructing one's own understanding and it should go beyond textbooks and rote drill. Whereas UG students and XII students still believed that learning physics is simply receiving knowledge from the authorities or textbooks and can be managed by rote learning. In the U.S. scenario, the initial favorable range was $41 \%$ [two-year college (TYC)] to 62\% [Dickinson College (DC)] and all groups showed no significant change in the post test. In Thailand this result was 48\% [30], whereas in Turkey the score was $31 \%-34 \%$ [31]. However, the A-D plot numbers lie much below the expert opinion in both pre and post tests for all groups, though the Indian teachers were closest to experts' view.

\section{Coherence cluster}

In the coherence cluster there were five items. Most of the faculty of physics thinks that physics should be seen as a coherent and consistent structure by the students. Students should be able to relate the facts with each other and rebuild the rest. Initially the favorable response range was 34\%$39 \%$. Only MS students showed a mild but not a significant improvement in this cluster. Both UG and class XII students showed deterioration in their scores [Fig. 1(b)]. In the U.S., the favorable response range was $42 \%-53 \%$ and in Thailand it was $45 \%$. In Turkey it was in the range $31 \%-38 \%$. In this cluster also the data points corresponding 

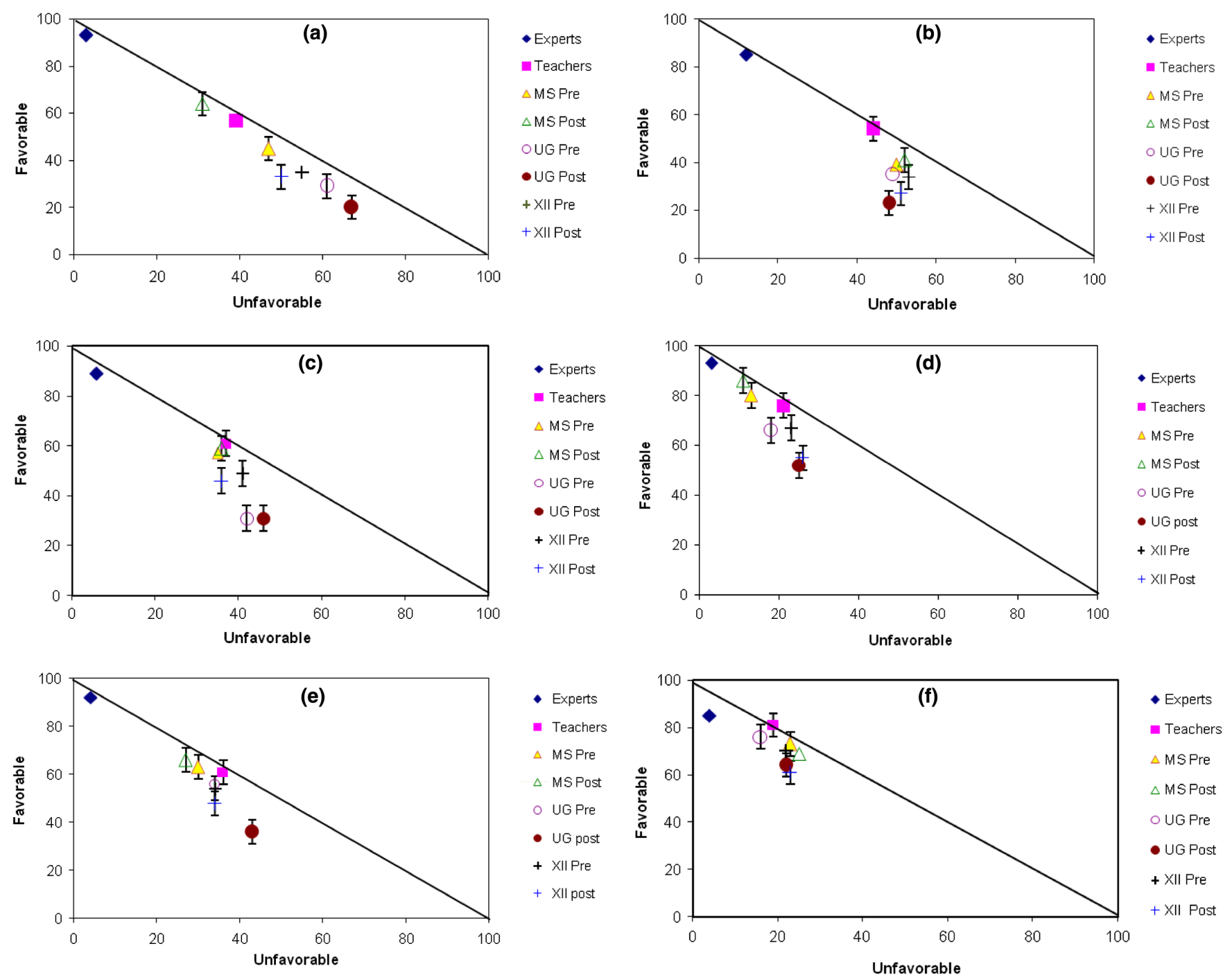

FIG. 1 (color online). A-D plots for (a) independence cluster , (b) coherence cluster, (c) concept cluster, (d) reality link cluster, (e) math link cluster, (f) effort link cluster of sample taken.

to each group lie much below the expert opinion both in pre and post tests for all the groups.

\section{Concept cluster}

This cluster consisted of five items, which probe the awareness of fundamental concepts of physics in problem solving. The initial favorable view was in the range $49 \%-$ $57 \%$. There was a slight, but again not a significant, improvement in MS students' favorable views [5]. Both UG and XII students again showed deterioration [Fig. 1(c)]. In the U.S., the favorable response range was $30 \%-47 \%$ and in Thailand it was 49\%. In Turkey it was 39\%. In this cluster also the data points corresponding to each group lie much below the expert opinion both in pre and post tests for all the groups.

\section{Reality link cluster}

This cluster has four items which probe whether students can link their learning with real life experiences. Students

had strong favorable responses, ranging from $66 \%$ to $80 \%$. Again, except for MS students which showed a significant shift, both UG and class XII students showed deterioration [Fig. 1(d)]. Thus, these students were not able to see a relation between physics and their experience. In the U.S., the favorable response range was $61 \%-76 \%$ and in Thailand it was $47 \%$. In Turkey it was in the range of 45\%-53\%. In this cluster, the A-D plot showed that the percentage of favorable view of MS students was above the Indian experts but below the U.S. experts' view.

\section{Math link cluster}

There were five items in this cluster which probed whether students consider math as a model to explain physical phenomenon or not. Students had favorable responses, ranging from $54 \%$ to $66 \%$. Again, except for MS students, both UG and class XII students showed deterioration in post test [Fig. 1(e)]. Thus, these students 
TABLE VII. Percentage of male to female students giving favorable to unfavorable responses on overall and clusters of the MPEX survey for pre and post test in India.

\begin{tabular}{lcccccccc}
\hline \hline Group & Overall & Independence & Coherence & Concept & Reality link & Math link & Effort link & $N$ \\
\hline Male (India) Pre & $56 / 35$ & $44 / 44$ & $34 / 54$ & $51 / 38$ & $70 / 20$ & $53 / 35$ & $70 / 22$ & 110 \\
Male (India) Post & $45 / 35$ & $46 / 37$ & $29 / 49$ & $40 / 39$ & $53 / 27$ & $47 / 35$ & $59 / 24$ & 110 \\
Female (India) Pre & $56 / 35$ & $40 / 50$ & $37 / 50$ & $48 / 42$ & $68 / 22$ & $58 / 32$ & $72 / 21$ & 155 \\
Female (India) Post & $51 / 36$ & $36 / 52$ & $29 / 53$ & $43 / 43$ & $63 / 21$ & $51 / 34$ & $66 / 22$ & 155 \\
\hline \hline
\end{tabular}

TABLE VIII. $t$-test results for comparison between male and female students' expectations.

\begin{tabular}{llllcc}
\hline \hline \multirow{2}{*}{ Group } & & $N$ & Mean & Standard deviation & $P$ value \\
\hline Coherence & Female & 155 & 16.2 & 3.19 & 0.358 \\
& Male & 110 & 15.8 & 3.92 & \\
Concepts & Female & 155 & 18.5 & 3.46 & 0.006 \\
& Male & 110 & 17.2 & 4.1 & 0.175 \\
Independence & Female & 155 & 19.0 & 4.28 & \\
& Male & 110 & 18.3 & 4.46 & 0.744 \\
Math & Female & 155 & 14.7 & 3.16 & 0.355 \\
& Male & 110 & 14.9 & 3.42 & \\
Effort & Female & 155 & 17.9 & 3.14 & 0.419 \\
\multirow{3}{*}{ Reality } & Male & 110 & 17.5 & 3.50 & 2.70 \\
& Female & 155 & 13.2 & 3.51 & \\
\hline \hline
\end{tabular}

were not able to see a relation between physics and math and rely just on memorization. In the U.S., the favorable response range was $58 \%-74 \%$ and in Thailand it was $41 \%$, whereas in Turkey the range of scores was $38 \%-45 \%$. Here in this cluster also the figures lie much below the expert opinion both in pre and post tests.

\section{Effort Link Cluster:}

This cluster has five items which probe how many students are trying to use available information effectively. It is observed that many students do not make proper use of information given to them in the class. They do not bother to take notes, and even if they take notes they do not use them properly afterwards. Surprisingly, initial favorable views of students started with a high percentage $70 \%-81 \%$, but deterioration in view was observed after instruction for a complete year [Fig. 1(f)]. In the U.S., the favorable response range was $66 \%-80 \%$ and it also dropped significantly after instruction. In Thailand it was $45 \%$. In Turkey it was in the range $47 \%-51 \%$. In this cluster the A-D plot showed that the views of UG students (pre) and Indian experts were almost in agreement with U.S. experts view.

\section{B. Genderwise analysis}

In order to find the difference in the expectations of male and female students, we calculated the percentage of male to female students giving favorable to unfavorable responses on overall and clusters of the MPEX survey, for pre and post test in India; see Table VII.
Furthermore, to examine the gender difference statistically, a $t$-test was carried out. The result of this test, Table VIII, revealed that male and female student groups did not differ in their scores on all the MPEX clusters except for the concept cluster $(p=0.006)$ on which female students (mean 18.5) had significantly higher average scores and less standard deviation than male students (mean 17.2).

\section{Countrywise analysis and inferences}

In order to compare the significant difference in the gains of students of different countries at different levels (masters, undergraduate, and school level), we made use of a $Z$ test, which is used for comparing proportions from two independent random samples. Table IX summarizes the results obtained, which are further discussed below for each category.

(1) College teachers. Comparative data clearly reveal that experts of the U.S. showed considerably higher favorable views in all clusters than their Indian counterparts, Table III.

(2) MS students. We compared and statistically analyzed the overall gain in pre and post test scores of University of Minnesota (UMN) university of the U.S., Dokuz Eylul University (DEU) of Turkey, and Kurukshetra University (KU) of India. To statistically compute the significant difference between the gains of students of these universities we used the $Z$ test for comparing two independent samples. The 
TABLE IX. $Z$ test results for countrywise comparison.

\begin{tabular}{|c|c|c|c|}
\hline & & $Z$ value & Critical value $( \pm 1.96)$ \\
\hline \multirow[t]{4}{*}{ MS students } & UMN (US) & 2.0 & Significant difference \\
\hline & KU (India) & & \\
\hline & DEU (Turkey) & 0.16 & No significant difference \\
\hline & KU (India) & & \\
\hline \multirow[t]{4}{*}{ Undergraduate students } & DC (US) & 0.03 & No significant difference \\
\hline & St. Bede's (India) & & \\
\hline & (Philippines) & 0.12 & \\
\hline & St. Bede's (India) & & \\
\hline \multirow[t]{2}{*}{ XII students } & TYC (US) & 0.65 & No significant difference \\
\hline & Schools (India) & & \\
\hline
\end{tabular}

result of the $Z$ test with $Z$ value (2.0) exceeding the critical value (1.96), as given in Table IX, indicates that there was a significant difference between the gain of U.S. (UMN) and Indian (KU) students, but between students of Turkey (DEU) and India (KU) the difference was not significant $(z=0.16)$.

(3) Undergraduate students. We compared and statistically analyzed the overall gain in pre and post test scores of Dickinson College (DC) of the U.S., St. Bede's College of India, and UG college of Philippines. We found statistically that there was no significant difference in the overall gain in all the colleges of these countries $(z=0.03$ and 0.12$)$; see Table IX.

(4) School students. We compared and statistically analyzed the overall gain in pre and post test scores of a two-year college of the U.S. and class XII students of India. The $Z$ test shows that statistically there is no significant difference in the overall gain in these schools of the two countries $(z=0.65)$; see Table IX.

\section{Overall analysis and inferences vis-à-vis objectives}

As expected, Figs. 2(a) and 2(b) show that Indian teachers and MS students have more favorable views as compared to UG and class XII students.

After instruction the unfavorable responses of students increased and favorable responses decreased in all categories except MS. This indicates that instruction given was not improving students' expectations about physics and most of the students were still having novicelike expectations even after the completion of the physics course. The study indicates that innovations need to be brought into the classrooms by teachers to improve the scenario to reach U.S. experts' standards.

Results also revealed that undergraduate students showed lower favorable expectations and higher unfavorable expectations than other classes.

MS students experienced a shift towards favorable attitudes in all clusters except the effort link cluster. The greatest difference in direction of favorable attitude was observed in the independence category, which is an indication of their maturity about the subject over the years.

UG and XII students showed relatively unfavorable expectations in the independence, coherence, and concept dimensions of the MPEX. This indicates that students considered the learning of physics as just the memorization of separate pieces of information given to them by their instructors and they were not evaluating it.

There were relatively favorable expectations shown by both UG and XII students in the reality link, math link, and effort link clusters. This indicated that students considered that ideas learned in physics are relevant to their outside experiences and they appreciate the role of mathematics in representing a physics phenomenon.

There is lot of difference observed between the results of experts (U.S.) and Indian teachers (experts in Indian
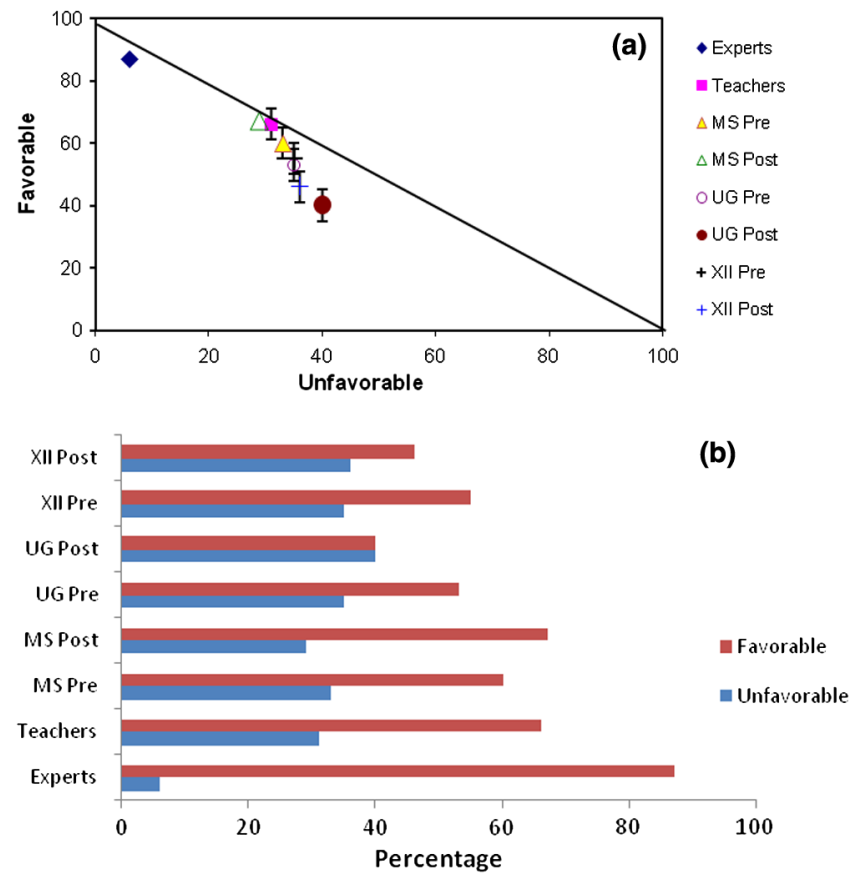

FIG. 2 (color online). (a) Overall agree-disagree plot and (b) overall percentage (favorable to unfavorable) of all groups. 
context) and also between experts (U.S.) and Indian students. In all clusters Indian teachers fell significantly below the U.S. experts' view response as given in the MPEX survey [5], pointing towards the need to drastically change the practices which they themselves follow in building their own knowledge structure and that of the students.

\section{CONCLUSIONS AND DISCUSSIONS}

The present cross-sectional study investigates epistemological attitudes and beliefs of Indian physics students at three different levels as well as those of Indian physics teachers (experts). These results are then compared to results of similar studies in four other countries. In this section, we summarize the answers to the research questions.

A. How do the overall attitudes and expectations of physics students compare between class XII (high school), undergraduate, and master's level of study?

We observed that there exists a difference in the attitudes and expectations of class XII, undergraduate (UG), and master's (MS) level students of India. In India, MS students had shown overall more favorable expectations in both pre $(60 \%)$ and post test $(67 \%)$ with an increase in their favorable scores from pre to post test as compared to undergraduate and class XII students scores ranging from $40 \%$ to $55 \%$ and with a decrease in the post test scores. This points to a worrying flaw in the formation of right beliefs and attitudes, resulting from an indifferent delivery system and lack of dialog between the teacher and those taught, leaving students with a superfluous learning experience leading them to abandon science as a stream of study, which is already worrying the science educators in the country.

In the U.S., Dickinson College students (UG) showed more favorable views than postgraduate and school level students. But the percentage of their favorable scores slightly decreased in post test. For other countries, Turkey, Thailand, and Philippines, data for only one level of students were available; therefore, it was not possible to make a comparison between different levels of students.

B. How do these expectations shift before (pre) and after (post) instruction?

Overall deterioration was observed in the attitudes, beliefs, and expectations of class XII and UG students in India, whereas MS students showed an increase in favorable expectations. After a discussion with our peer group it was felt that the positive shift in MS students' expectations can be due to the fact that only those students who are really interested in studying physics opt for doing master's level work, whereas XII and UG students study physics along with other subjects like mathematics, chemistry, etc., and at this stage they have limited attention.

In the U.S., all high school, UG, and MS students showed deterioration. MS students of Turkey also showed deterioration. Only UG students of Philippines showed an increase in their expectations after instruction. Data for pre-post comparison was not available for Thailand students. The increase in unfavorable responses and the decrease in favorable responses indicates that students' expectations were not improving even after a year of physics course and the instruction given was ineffective in taking their expectations towards an expert and raises questions about the instruction methodology being followed in the classroom.

We also compared the expectations of Indian teachers with XII, UG, and MS students to find significant differences in their expectations and observed that Indian teachers' expectations (experts in country) are significantly higher than students' expectations in the coherence, concept, and effort link clusters.

C. Is there a difference in expectations between male and female students?

This comparison was done in the Indian context only as data required for this were not available for the other four countries. Indian male and female groups did not show any significant difference in their expectations in any cluster, except for the concept cluster $(p=0.006)$. In this cluster female students (mean $=18.5)$ had higher average scores with less standard deviation than male students (mean $=$ 17.2). This may indicate that female students are giving more attention to the understanding of concepts than their male counterparts, but this may not be taken as conclusive evidence for gender difference.

D. Does nationality play a role in expectations?

In all countries (U.S., India, Turkey, Thailand, and Philippines) the basic trend of expectation from pre to post test remained the same; i.e., a decline in expectations at the secondary school and undergraduate level was observed. Indian MS students were an exception.

A significant difference was observed in the expectations of U.S. experts and Indian teachers.

The score of favorable views of Indian UG students was observed to be less than U.S. students [DC and Public Liberal Arts University (PLA)] in the independence, coherence, reality link, and math link clusters. The XII students of India also showed less favorable responses than U.S. (TYC) students in the independence, coherence, reality link, math link, and effort link clusters.

This raises questions about the possibility of cultural differences between the two sets of students as well as teachers (U.S. and India). This can be a language barrier at the XII level when students make a switch from their medium of instruction in vernacular to English and are in a transition period, or it may be that in India less emphasis is given in making a connection between concepts and ideas with real life at school and college level about which authors have a personal experience. Generally, in India physics is taught as a theoretical monologue, with significant emphasis on deriving the formulas with little connection between the theory being taught in the classroom and experiments conducted in laboratories and linkage with real life. In fact, there is a near absence of hands-on experience. 
An important implication of the present study is that it is important for Indian physics educators to improve the situation by bringing synergy between classroom, laboratory, and real life exposure to the phenomenon of physics in a larger context of identified expectations particularly at the XII and UG levels, for which a sensitization program must begin from teachers whose views fell short of the U.S. experts.

\section{SUMMARY}

In this study, we explored student attitudes, beliefs, and expectations by focusing on Redish's six clusters: independence, coherence, concepts, linking physics with real life, with math, and the effort students expect to make in the process of learning physics using the MPEX survey. We used this survey for three categories of students studying physics at XII (high school), UG, and master's levels. We conclude that overall most of the students still have novicelike expectations even after the completion of a full year of physics instruction. They possibly are not developing a deep understanding of physics concepts as a result of traditional instruction of physics courses. This may affect their motivation and success in the course as well as career choices. Therefore, we conclude that there is a strong need to pay attention to learners' beliefs, attitudes, and expectations when they come into the classroom, and effort should be made to transfer their novicelike view to expertlike view by employing certain PER-based strategies, like concept tests and Peer Instruction [33], just-intime teaching [34], interactive lecture demonstrations [35], etc. Research has provided strong evidence that such PERbased strategies can increase conceptual as well as expectation gains [36-39]. One of the recommendations that can be made from this study is that it would probably be productive to experiment with ways to adopt PER, for example, Peer Instruction, in ways that are compatible with the different local contexts within India. This can reveal cultural differences across a vast country like India. To undertake this task a national collaborative effort at the level of apex institutes and Association of Physics Teachers is desired, as this is likely to provide a mapping of these differences through PER, which, given the diversity of the country, should include social indicators such as caste, income, and ethnic groups as a set of important parameters. We intend to undertake such a collaborative study in the future.

\section{ACKNOWLEDGMENTS}

This study has been a joint effort based on a diverse set of data sources. We could not have assembled this data set without the cooperation and efforts of many individuals and institutions. We express our gratitude to all the participants of this study and the reviewers for their very valuable suggestions.
[1] M. Schommer Effects of beliefs about the nature of knowledge on comprehension, J. Educ. Psychol. 82, 498 (1990).

[2] D. B. May and E. Etkina, College physics students' epistemological self-reflection and its relationship to conceptual learning, Am. J. Phys. 70, 1249 (2002).

[3] D. Hammer, Student resources for learning introductory physics, Am. J. Phys. 68, S52 (2000).

[4] B. Sherin, Common sense clarified: The role of intuitive knowledge in physics problem solving, J. Res. Sci. Teach. 43, 535 (2006).

[5] E. F. Redish, J. M. Saul, and R. N. Steinberg, Student expectation in introductory physics, Am. J. Phys. 66, 212 (1998).

[6] A. Elby and D. Hammer, On the substance of a sophisticated epistemology, Sci. Educ. 85, 554 (2001).

[7] L. Lising and A. Elby, The impact of epistemology on learning: A case study from introductory physics, Am. J. Phys. 73, 372 (2005).

[8] W. M. Roth and A. Roy Choudhury, Physics students' epistemologies and views about knowing and learning, J. Res. Sci. Teach. 31, 5 (1994).

[9] A. Collins, J.S. Brown, and S. E. Newman, in Knowing, Learning, and Instruction: Essays in Honor of Robert
Glaser, edited by L.B. Resnick (Lawrence Erlbaum, Hillsdale, NJ, 1989), pp. 453-494.

[10] A. Schoenfeld, Mathematical Problem Solving (Academic, New York, 1985).

[11] B. A. Thacker, Recent advances in classroom physics, Rep. Prog. Phys. 66, 1833 (2003).

[12] R. J. Beichner, An introduction to physics education research, in Getting Started in PER, edited by C. Henderson and K.A. Harper (American Association of Physics Teachers, College Park, MD, 2009), Vol. 2 [http:// www.per-central.org/items/detail.cfm?ID=8806].

[13] Michelene T. H. Chi, Conceptual change within and across ontological categories: Examples from learning and discovery in science, in Cognitive Models of Science: Minnesota Studies in the Philosophy of Science, edited by R. Giere (University of Minnesota Press, Minneapolis, MN, 1992), pp. 129-186

[14] A. Elby, Getting started with research on epistemologies and expectations, in Getting Started in PER, edited by C. Henderson and K. A. Harper (American Association of Physics Teachers, College Park, MD, 2011), Vol. 2 [http:// www.per-central.org/items/detail.cfm?ID=10578].

[15] E. F. Redish, Introducing students to the culture of physics: Explicating elements of the hidden curriculum, AIP Conf. Proc. 1289, 49 (2010). 
[16] E. F. Redish, Teaching physics with the Physics Suite (John Wiley \& Sons, New York, 2003).

[17] K. Semsar, J. K. Knight, G. Birol, and M. K. Smith, The Colorado Learning Attitudes about Science Survey (CLASS) for use in biology, CBE Life Sci. Educ. 10, 268 (2011).

[18] I. Halloun and D. Hestenes, Interpreting VASS dimensions and profiles for physics students, Sci. Educ. 7, 553 (1998).

[19] A. Elby, Helping physics students learn how to learn, Am. J. Phys. 69, S54 (2001).

[20] W. K. Adams, K. K. Perkins, N. Podolefsky, N. D. Finkelstein, and C.E. Wieman, A new instrument for measuring student beliefs about physics and learning physics: the Colorado learning attitudes about science survey, Phys. Rev. ST Phys. Educ. Res. 2, 010101 (2006).

[21] E. F. Redish and D. Hammer, arXiv:0807.4436.

[22] P. K. Ahluwalia and S. Sharma, Epistemological beliefs, expectations and physics learning, Special Issue on Physics Education Research, Phys. News: Bull. Indian Phys. Assoc. 41, 58 (2011).

[23] http://nces.ed.gov/surveys/pisa/.

[24] E.F. Redish, in A Theoretical Framework for Physics Education Research: Modeling Student Thinking, Proceedings of the International School of Physics "Enrico Fermi," Course CLVI, edited by M. Vicentini and E. F. Redish (IOS Press, Amsterdam, 2003).

[25] N.G. Tomasini, in Teaching Physics from a Cultural Perspective: Examples from Research on Physics Education, Proceedings of the International School of Physics "Enrico Fermi," Course CLVI (Ref. [24]).

[26] V. M. Mistades, How do education students learn physics?, U.S.-China Educ. Rev. B 4, 457 (2011) [http://www .davidpublishing.com/davidpublishing/Upfile/12/8/2011/ 2011120803344457.pdf].

[27] V.M. Mistades, Exploring business students and liberal arts students beliefs about physics and physics learning, Asia Pac. Educ. Rev. 8, 100 (2007).

[28] S. Mehmet, Correlations of students' grades, expectations, epistemological beliefs and demographics in a problem-based introductory physics course, Int. J.
Environ. Sci. Educ. 4, 169 (2009) [http://www.ijese.com/ IJESE_v4n2_Sahin.pdf].

[29] N. Kritsadatana and P. Wattanakasiwich, Freshmen and physics teacher expectations in learning physics, in Proceedings of the ACSME Conference on Teaching for Diversity-Challenges and Strategies, 2011 (UniServe Science, Sydney, Australia, 2006).

[30] K. Chanprasert, The expectations of students from the faculty of nurse on learning life science physics, in Proceedings of the 34th Congress on Science and Technology in Thailand, 2008, CD ROM.

[31] S. Mehmet, Exploring university students' expectations and beliefs about physics and physics learning in a problem-based learning context, Eurasia J. Math. Sci. Technol. Educ. 5, 321 (2009) [http://www.ejmste.com/ v5n4/EURASIA_v5n4_Sahin.pdf].

[32] A. M. Dalagan and V. M. Mistades, Students' beliefs and attitudes toward learning in physics component of the Lasallian (General Education) core curriculum, KBM J. Sci. Educ. 1, 1 (2010).

[33] E. Mazur, Peer Instruction: A User's Manual (PrenticeHall, Upper Saddle River, NJ, 1997).

[34] G. M. Novak, E. T. Patterson, A. D. Gavrin, and W. Christian, Just- in-Time Teaching: Blending Active Learning with Web Technology (Prentice-Hall, Upper Saddle River, NJ, 1999).

[35] D. R. Sokoloff and R. K. Thornton, Using interactive lecture demonstrations to create an active learning environment, Phys. Teach. 35, 340 (1997).

[36] Tolga Gok, The impact of peer instruction on college students' beliefs about physics and conceptual understanding of electricity and magnetism, Int. J. Sci. Math. Educ. 10, 417 (2012).

[37] E. F. Redish and D. Hammer, Reinventing college physics for biologists: Explicating an epistemological curriculum, Am. J. Phys. 77, 629 (2009).

[38] Catherine H. Crouch and E. Mazur, Peer Instruction: Ten years of experience and results, Am. J. Phys. 69, 970 (2001).

[39] J. M. Saul and E. F. Redish, "Evaluation of the Workshop Physics Dissemination Project," University of Maryland, 1997. 